\title{
Greek University Candidates' Targets in a Changing, Unstable and Unpredictable Economic Environment
}

\author{
Kalerante E. ${ }^{1}$, Mormory P. $^{2}$ \& Mormoris $\mathrm{M}^{3}$ \\ ${ }^{1}$ Lecturer, University of W.Macedonia, Greece \\ ${ }^{2}$ Researcher, University of Piraeus, Greece \\ ${ }^{3}$ Director of Higher School, Greece \\ Correspondence: Kalerante E., Lecturer University of W.Macedonia, Greece. E-mail: ekalerante@yahoo.gr \\ Received: May 16, 2013 \\ Accepted: June 1, 2013 \\ Online Published: June 12, 2013 \\ doi:10.5430/ijhe.v2n3p12 \\ URL: http://dx.doi.org/10.5430/ijhe.v2n3p12
}

\begin{abstract}
The topic of the present study is concerned with the university candidates' educational and career choices against an unstable economic background that may necessitate the reformulation and readjustment of choices to innovative concepts of advancement and future development as they may apply to youngsters of different social class and gender. The sudden call to precipitated maturity is a shock, as eighteen- year olds are now expected to sit for exams and simultaneously opt for an education- conduit to vocational security.

More specifically, a case study concentrating on two different geographical areas: the Northern suburbs and western Attica was designed, taking into consideration the class-related socio-economic and political traits of their population. It is also estimated the extent to which educational choices are determined by gender.

Close and open- end questions are utilized to unravel the societal considerations and selection tactics of the subjects, which is semantically revealed to lead to gingerly realistic steps on the quick sand of political and economic instability.

There was also considerable profit from a multitude of interpretative versions and research bibliographies, so as to uncover the role that gender and class-related inequality plays in shaping and directing educational and vocational choices.

The crux of our problematic is centered in a liquid status quo with individuals making judgments according to the social and educational capital established in the class and gender-related correlations within the collectivity.

The research proceeds to expose vast vistas of continually re-definable prospects, renewable explorative models and a systemic complexity that regenerate youngsters' choices.

It is noteworthy that information has for the first time become available on education being tied to vocation, not only against the backdrop of an economic and value crisis but also the end decade- long governmental providence.
\end{abstract}

Keywords: Social class, Gender, Re-difinable prospects, Explorative models, Youngsters’ choice

\section{Introduction}

In the present research, we make an attempt is made to see how the emerging financial instability and, generally, the existing flowing insecurity affect the candidates' choices in the Tertiary Education. In the researchers' perspective, the content of argumentation, the candidate's rational about his choice and, generally, his viewpoints about the estimation of the current socio-economical conditions as well as the appeal on the future to come are studied. In the Greek society the role of the family is rather significant since there is a strong linkage among its members and it is important to mention from the beginning that the candidate's choice is defined in terms of the family's choice. The entrance in Tertiary Education is what the Greek family asks for and invests on education or, better to say, on the acquisition of degrees which, especially for the middle and lowest social strata at least until today, have been connected to social mobility and the elevated social status. The Greek family's targets, in specific, are the acquisition of a position in the public sector where the stability of an income, the permanency of a labor relationship and the potential of free time are secured. 
Therefore, the entrance in Tertiary Education has been connected to the acquisition of qualifications that would formulate a future which would be characterized by stability and safety. The public sector is open to the public and within this environment the political system has been setting the labor positions within a large number of sectors by preserving a powerful client-like relationship between the politicians and the people, by undermining the citizen society and not promoting transparency, the unimpeachable procedures and the meritocracy in the public sector. In general, it could be said that until 2009 it seemed that the Greek society was setting even higher targets for the prosperity of its members, by participating in the consuming society which focused on the material delight, under the belief that the progress of its members through the preservation of high incomes and the quality of life was presumed. Gradually, even the lower strata have started to adopt attitudes and behaviors of the higher social strata and to introduce themselves to utopian schemes of technical prosperity giving the impression even of the bluntness of social inequalities.

The function of the individuals' education was based on two levels: a) within the range of educational institutions of primary and secondary education and b) on the supplementary tutorial institutions. The second level of supplementary courses, particularly of the supporting courses, was considered necessary for the entrance into Tertiary Education. The Greek family was investing a financial capital on the entrance of its members into university studies or on the attendance of universities abroad. Simultaneously, the years of attendance were increased beyond the 9-year compulsory attendance resulting to a $60 \%$ of the students turning themselves towards Tertiary Education. Besides, great emphasis was placed on postgraduate studies, masters and doctoral degrees connected to the acquisition of high rank positions within the labor sectors, in an attempt to secure the horizontal social mobility within the labor environments.

Since 1980, reference can be schematically made to a systemization of targets right after the political changeover, through the reinforcement of the middle class income and the construction of an ideology about the unhindered progress and success. Throughout that period and until 2009 the Greek family invests money, as it has already been mentioned, on tutorial courses for the entrance into the Tertiary Education as well as on foreign language courses, especially English and French. The acquisition of such qualifications is placed more within the acquisition of typical qualifications and less on the substantial education. At the same time, students are apparently occupied with the so-called "decorative education" such as ballet, dance, painting and music. This is about a supplementary qualification package connected to the imitation or adoption of attitudes and perceptions of the higher social strata. This decorative education was connected to the free time which had also to get programmed in such a way so that it was disposed for the benefit of the educated individual aiming at the social mobility and, in general, the prestige gained through success of the member and the whole family. The phrase by which the Greek family states its participation in the education of its members is rather characteristic, mentioned especially by words such as: "We take the examination $\{\ldots . .$.$\} " or "We have studied all the subjects".$

In the present research, an attempt is made to see if this attitude towards education has been differentiated and, generally, how the educational expectations or estimations are formulated during the period of financial crisis which we currently experience.

\section{The Greek Educational System}

The Greek Educational System is characterized as an open educational system giving students the potential, without a severe examination system, to complete the 12-year attendance and without exclusions for a large amount of students about $70 \%$. This observation is important because opportunities structures mainly for the middle and lower strata are theoretically familiarized with the educational system, the language and generally with the educational culture so that the possibilities to enter Tertiary Education after a 12-year attendance are increased. Therefore, since the students do not confront any exclusions as from the first years of their attendance in the primary or secondary education, for example, examinations on a national level, the Greek family, particularly during the last year of attending the secondary education, reinforces the students with supplementary courses trying to align, exclusively, with the volume of subjects to be examined. This choice is not connected to the filling of gaps or deficiencies in which case discussion could be made about a more substantial knowledge, but it is based exclusively on learning in a parrot -fashion meanings, terms and exercises, as it is usually the case in the educational system, so that the student succeeds without any demand on the substantial knowledge concerning the subject of his/her studies. As it has already been pointed out, the number of students being candidates for Tertiary education as well as that of the successful ones is especially high. This issue is connected, on the one hand, to a system without national examinations in the primary and secondary education and on the other hand to the limited amount of subjects to be examined for the entrance into the superior educational institutions. 
In particular, the subjects to be examined are standardized both at school and the tutorial courses so that they can be learnt more by heart and be less understood by the students since the question here is not the education or the familiarization with scientific fields. At this point, both school and tutorial subjects are observed to concentrate on the typical learning and are not connected to the cross-curricular and interdisciplinary approach, even though they should be promoted and reinforced within the educational environment as principles.

During the past years, a non formal pattern of education has been observed. The tutorial institutions acquire a particular meaning for the Greek family because the tutorial education is connected to the more systematic standardization of the subjects to be examined and to the improvement of learning techniques as well as to the estimation for the possible questions that will be posed during the exams. The fact that a large number of students do not attend school classes during the last two months is rather indicative. On the contrary, concentration is placed on their tutorial classes which are regarded as more efficient to fulfill their objective. Thus, an anomic situation within education is formulated, on the one hand, with dysfunctional schools during that time period and on the other hand with their questioning as educational institutions. At this point, it could be said that this issue must be the preoccupation of the state which should re-examine the model of the educational policy, basically both the system of the content of subjects to be examined and the examination system.

\section{The policy of rights within the Greek society}

A distinctive feature of the Greek society is that both boys and girls are reinforced by their families with tutorial, mainly, courses in order to succeed in a superior educational institution. The Greek society is aligned with the western culture in terms of rights for both genders. Even though there are different perceptions and attitudes regarding gender which absolutely concern the social scientists, it could be said, in general, that the university education for girls is chosen by all the social strata, even if the approach on the women's education is different according to the social stratum in which they belong. In particular, as from 1980 and afterwards special emphasis was given to the projection of the women's rights with the implementation of a special legislation by granting social rights in many fields. Moreover, the different confrontation of women in the labor environments was raised, especially for issues of evaluation and professional evolution, but this does not mean a full equality of rights. In general, it could be said that the Greek legislation and the Greek society do not exclude women's education in Tertiary education. At this point, it should be underlined the fact that the researches are concentrated on the students' performance in relation to their gender. It is assumed that boys tend to choose exact sciences directions whereas girls choose rather theoretical sciences. Besides, special emphasis is given on the issue of choosing the subject of their studies. The girls have considered their studies and the acquisition of a professional position as a means to secure an additional income to what the "breadwinner" would bring. It should also be added to the above mentioned points that even better conditions for women both in educational and labor environments have been gradually formulated. Especially throughout the so-called period of special prosperity, as it is defined from 1980 until 2009, the women's participation in the political, labor and social fields which were previously possessed by men is observed. The Greek culture has been gradually changed giving women the potential to take advantage from a series of rights towards a course of equality for both genders. The perspective of choices based on gender regarding choices, attitudes and perceptions is of special interest and it should be examined if the issue of educational choices and, moreover, of professional choices affects the candidates for the superior educational institutions.

As it has already been mentioned, during the period 1980-2009 special emphasis was given on the promotion of rights for citizens' equality; a course which is parallel with the European policy for rights. In Greece, a bluntness of social inequalities, a participation of the lower strata in the centers of decision making, a function of social mobility, a reinforcement of the educational right by rendering free education in all grades, high wages and implementation of welfare programs within the framework of a powerful "welfare state" have been observed. Thus, expectations were created for the potential of improving the citizen's life and reduction of inequalities. In the present research, interest is placed on the fact whether there is differentiation regarding the choices made according to the social strata and how the socio-economical conditions are re-interpreted within a framework of increased unemployment, escalating insecurity, reduction of the welfare-state supplies and, in general, liberation of the system.

\section{The Setting: Western Attica \& Northern suburbs of Athens}

The research is concentrated on the two areas of Western Attica and the Northern suburbs of Athens. The researchers' choice was based on the different socio-economical data of the two areas. Western Attica, which is characterized as a downgraded area, is an area with low financial level and low educational and social capital citizens. Ever since 1990 an increased number of immigrants has been concentrated there, mainly from Albany and the former communist countries as well as repatriated Pontiacs. It is an industrial area and a large number of residents there comprise the 
labor force of the town. In the Northern suburbs of Athens, the residents are individuals with high incomes and high educational and social capital. They participate in the political decision-making centers, they are better informed and their professions are rather prestigious, such as lawyers, doctors, businessmen etc. There is a general sense that this is an area of the "elite" addressing to specially privileged citizens group as being part of the system. It is mainly characterized as a pure residence area, with a particular natural environment connected to the quality of life of the higher social strata where people live "protected" and far off the downtown area and the downgraded areas of Western Attica. The estimation is that, since reference is made to different groups of population, there will be a difference in terms of interpretation of the current situation that is in terms of understanding the socio-economical conditions as well as of the perception about the future, the expectations and wishes of their children. At the same time, the financial crisis has already affected the residents of Western Attica. In particular, it is assumed that it affects the educational and professional decision making of their children.

\section{Data collection and analysis}

The sample consists of 18 individuals from Western Attica and 22 ones from the Northern suburbs, out of which 6 girls and 12 boys from the first area and 14 girls and 8 boys from the second one. All sample individuals are 18 years old. The research was conducted during the school year 2009-2010, in April, before the examinations and the filling of the application form to choose their schools. According to the system of choices in Tertiary education, the students sit the examinations according to the direction they have chosen, exact, theoretical and technological. The exams are usually conducted in May and after the grades announcement per subject the filling of the application form follows in which the candidates fill in the schools of their interest. The research was chosen to be carried out in April so that considerations, estimation and preferences about their education and profession were collected before they sit the examinations when they would probably link their performance to their preferences. The collection of the most representative answers about their educational and professional choices was aimed. For the area of Western Attica, especially, school teachers were contacted so that the following categories would be included in the sample: a) male and female students whose families' educational and social capital is high with 1) low school performance and 2) high school performance and b) male and female students whose families' educational and social level is low but with high school performance. In the Northern suburbs the following were utilized for the sample: a) the criterion of high educational, financial and social capital and low school performance and b) the criterion of high educational, financial and social capital and high school performance.

A questionnaire was used, which was filled at the researchers' presence, with an open question towards the students asking them to answer how they imagine their professional situation after 6 years. In the close questions, they should answer on how well informed they are about the schools of their choices, whose viewpoint was taken under consideration, which were the criteria for their choices and if they had the same importance, the professional security, the financial perspective, the profession correlation and the personal satisfaction. They were requested to grade these 4 parameters or to add more ones. In order to see the role of the family in the choice of profession, they were asked to present the criteria with which their parents would choose a school for them and which school that would be. In the following question they were requested to evaluate professions. A question supplementary to the previous one was to categorize professions based on the financial insecurity (risk). After the questionnaires were filled and collected, a semi-interview followed in order to clarify the questionnaire answers or to investigate more issues. Most of them emerged out of the last question, the open one, in which they should present future perspectives and which was insufficiently answered, but lacking data. This was a realization of the children's unwillingness to answer the question through written discourse. At this point, reference is made to the problems of the researches with open questions which the individuals being questioned avoid either due to their limited written expression or because they are afraid of the researcher's disapproval. The semi-interview provided the potential to scrutinize issues that were necessary to be clarified. It is particularly positive the fact that there are 3 researchers who had first obtained the questionnaires and conducted the semi-interview afterwards. After the questionnaires had been studied, a viewpoint about the candidates' profile was formed. Each one's answers were categorized and the data to be investigated were filed in their portfolios after process and viewpoint exchange by the researchers. At this point, it should be underlined the researchers' different research fields in which one engaged oneself more with gender issues, another one with social strata issues and another one with education organization issues. Therefore, throughout all the stages of constructing questionnaires and semi-interviews as well as utilizing observations, a blending of elements and co-estimations took place. 


\section{Findings}

The categorization made in Western Attica and the Northern suburbs was of assistance in studying factors such as the gender, social class and educational capital that contribute to the formulation of educational and professional choices. It was found out that in the first category, the area of Western Attica, the issue of high educational capital plays a significant role in the formulation of choices and attitudes over the future choices. On the contrary, the low educational capital does not create the conditions necessary to support even those students that have a high school performance. In the Western suburbs, the low or high students' school performance does not seem to be evaluated by the families with high educational, financial and social capital.

\subsection{Special points from the Western Attica sample}

In terms of gender, female students coming form families with low educational capital were observed to have stated that they were insecure and especially preoccupied about their future, especially in cases of having brothers in the family. Maria's answer, whose performance was 18,2 during the third term, that is almost excellent as per the 20 grade scale, was indicative:

"I would like to become a doctor. I am not sure if I can apply for all the Medical Schools in Greece. I will apply only for the Medical School of Athens and following all other schools of Athens in my field".

When she was asked what she would do had she succeeded in the Nurse School of Athens, she replied that she would be "happy" because she would not be a financial burden to her parents and to her knowledge "nurses are currently engaged in jobs". A common element in all the female interviews was that the issue of their parents was addressed with a particular sensitivity and understanding. The fact that they were concerned about unemployment or their parents' increased labor hours or their possibility of unemployment was particularly emphasized and they stated that they would not like to weigh their parents down. The difference lies in the families with a higher educational capital in which the girls, despite of their sensitivity, a typical traditional gender stereotype, stated that they wished to study but their optimism concerning the future of both their families and themselves was temperate, and especially in the cases with a high financial capital their targets seemed unaffected by the financial crisis. Ioanna's comment is indicative:

"I will study Psychology. I read Miller's books, I like psychoanalysis. It is nice to learn about people and explore their soul. To the question, whether she could practice the profession, the answer was that she was not interested in this issue at that moment. She was interested in becoming a student, then a psychologist and then she would see. In the pressing question how she imagined herself after 6 years her answer was limited to that she would become a psychologist without any connection to the labor market".

Male and female students coming from families with low educational and social capital were particularly preoccupied about their future and were already pessimistic with a feeling of inferiority which was interpreted by them with their even decreasing access possibilities in the consuming society. Aleko's answer is indicative here:

"Now, I am just like the immigrants \{....\}. A pair of trousers, a shirt, neither a cinema, nor a coffee shop \{....\}. I do not want to say what I will do in the future because I do not know".

Male and female students with a high educational and social capital downgrade the role of the school regarding their informing about schools, the potential of their occupation and, in general, the education provided. On the contrary, they underline the positive role their families and tutorial institutions play. Ioanna B's answer is indicative:

"My mother and I searched the Internet about every school. The teacher at school gave us an old book that did not include all the schools of Tertiary education. He, himself, was not aware of the subjects taught in each school and what we can do on a professional level \{...\}. Imagine, he taught professional orientation!".

There are a number of boys stating that if they can not find a job in Greece they will go abroad. In particular, the boys coming from families with a high educational capital state that they will combine their staying abroad for a job with a primary preference to countries such as the USA, "the American Dream is still alive", England, Germany. Nico's answer is rather indicative:

"I know all the countries \{...\} I travel through the Internet, I can go everywhere. I will stay in Greece only in the case I find a job. I can not be a poor person $\{\ldots\}$..."

The issue of profession and studies is rather profound among the children coming from families with a low educational capital. The cognitive fields issue as well as the information about the content of their studies is not of their particular interest. On the contrary emphasis is placed on their professional perspectives. Their answers that they would not study without being sure that they would have a job are indicative. Even among the male and female 
students with high school performance there is a tendency not to proceed into further studies. What is directly important is to get involved in any kind of job. Helen's answer is indicative:

"If I found a job right after senior high school graduation in a mall I would go there and I would take care of my studies later on".

Individuals coming from families with a high educational capital continue to believe to the necessity of an education before entering the labor market. In their application form they state, mainly the boys, that they will choose schools of their interest taking into consideration their professional perspective. Ilia's point of view is indicative:

"I would like to become a pilot, like my father who is a pilot in the Olympic Airways. But Olympic airways do not exist any more and pilots are currently paid less and work more. Should I go to England to study? I will see. I will probably apply for Civil Engineer \{...\} Eh...I will do something anyway”.

The girls coming from families with a high educational capital and wishing to engage with artistic fields have been mainly preoccupied with the financial crisis issue. Anne B's answer is indicative. She states:

"I would like to become a dance teacher. I attend a ballet school, but, nowadays, who is going to send his children to a ballet school? \{....\} I should better do something else and dance alone in front of the mirror".

Children coming from families with a high educational capital state that they are going to decide together with their parents about the school they will choose, meaning that they will also project or express their personal wish about a school. In general they are very cautious since the analysis of their texts content would show the repetition of the words "under the current financial conditions" or "now that things are difficult" stating that they do not want to risk anything or that they are afraid of not being well informed about the professional perspectives. The boys, especially, realize that their parents address other professional vehicles or acquaintances and all together get advice from specialists in order to decide resulting in that the boys face a difficulty in taking the risk to illustrate their points of view. Aleko's observation is indicative:

"Every day I listen to the phrase "you are a boy and we must see what you will do with your life". What would be different if I were a girl?"

In this case the girls seem to be more liberated and perhaps the "breadwinner" stereotype comes back. Therefore, they will occupy themselves with something supplementary meaning that a marriage would be a good solution, especially if the man has a job or a high income. This issue was particularly intense in cases of twin siblings in which there is one boy and one girl within the same family. The boy comments that his parents have become expertise in the fields of mechanics or computers in the sense that they continuously investigate schools and professional fields. He feels that the whole family focuses on his own future in literary terms. Even though his sister has a better school performance and moves towards the same direction, parents preoccupy themselves with her in the least. Ilias (the brother) indicatively states:

"I am very curious about what will happen in the end. They will end up with me about what school to apply for and what to do \{...\}. Will they let my sister alone to decide at the end? Or, will they announce to her "we have both decided that you two should apply for these schools","

Among the families with a low educational capital, the issue of professional perspectives about the child is set mainly by the father. Mother's role is rather supplementary while both boys and girls, having perceived primarily the financial status as a direct dependence mainly from the father's job, do not seem to react and do not risk by projecting a different proposal. A kind of solidarity is formulated among the members either to maintain the income gained or to remain within the working mainstream so that they will have some income. They are afraid of the marginalization and social exclusion. A common element of the families with a low educational level and a high educational level in Western Attica is the increasing preference (75\% for high educational capital families and $45 \%$ for low educational capital families) towards police and military academies, an issue connected to the professional risk limitation. Thomas' answer, who is a member of the Communist Youth of Greece (KNE) and whose father is a worker and trade unionist in the Communist Party of Greece (KKE), is indicative. He states that the police academies are his primary choice.

In the question about which are the criteria for his choice he gave a single-word answer: professional, whereas in the pressing question about how the professional choice is combined with the ideology, he preferred not to give an answer.

Another important observation is that in the open question of the questionnaire and before the interview about how they imagine their professional status after 6 years, an $80 \%$ of the children with low educational capital answered: 
"having a job", whereas an $85 \%$ of the children with a high educational capital answered: "having a job on what we studied".

\subsection{Special points from the sample of the Northern suburbs}

Male and female students coming from the Northern suburbs were discussing with ease about the financial crisis highlighting the consequences on other individuals. The observations of some girls who were trying to project their families' social status and the boredom they had been experiencing before the crisis in an environment where, as they stated, everybody was equal are indicative. Angie's observation is of special interest. She comments:

"I was tired of meeting in the cafeterias of Kifisia the students playing truants from all schools of Athens. Now we have calmed down. I detested them. They were niffy $\{\ldots\}$ "

As far as the professional choices are concerned they stated freedom of choice. Their attitude and behavior depicts the prestige and culture of the upper social class. They lived every moment. The preoccupation about the profession might not bother them were it not obligatory to fill in the application form just to choose a school.

At this point it should be commented that $35 \%$ of the female students with high school performance and $45 \%$ of the male students were already attending tutorial courses and disdained the Greek system as they were typically completing the secondary education while they were preparing themselves with intensive courses for the IB. Maria's point of view is indicative. She states that:

"I can not get myself into stress and succeed in a school in which I am not interested. I want to live abroad, to be alone and do whatever I want. I am bored here".

Regarding the same issue John observes that:

"I can go wherever I want, to choose what I want as long as I say it. I am leaving $\{\ldots\}$ ".

All the students of the sample attending IB courses are students of private schools, and, as they stated, it is very common for those that take the IB not to be interested in the subjects taught in the $2^{\text {nd }}$ and $3^{\text {rd }}$ class of Senior High School. It is important that the Ministry of Education, in order to allow them to involve themselves only with the IB, even if they had to disdain the school institution, released them from the national exams.

Male and female students attending public or private schools and having not obtained the IB undermined the role of school in the $3^{\text {rd }}$ class of Senior High School giving more emphasis on the increased private courses meetings. They choose to attend private courses for the subjects of their direction and the teachers they address to are teachers of significant qualifications. The parents or the student usually study the teacher's portfolio and decides or decide if they are going to hire him/ her or not.

In contrast to the Western Attica students who use up the permitted number of preferences, choose an exclusively limited number of schools, those that are connected to the increased prestige towards each direction. Thus, they apply for the Law School, the Medicine School, departments of Economics, Polytechnic Schools and Computing Schools whereas they do not apply for schools without professional rights or with ambiguous subject of studies or technological training institutions. They collect information about the schools from the Internet and their tutors and they seem to simply announce their decisions to their parents. The point on which emphasis is given is the professional continuation that is they take under consideration that their parents gained money and social status through a profession. This has a reinforcing function conducive to choosing the same field. Even if they were free to choose something different, the fact that they are not forced to start their professional career from zero and that there is something ready waiting for them gives them joy. What should be underlined here is that even though the choice of profession seems something compulsory, male and female students activate their potentials for the disposition of their free time. Both in their social class culture and in the educational opportunities they have mainly in the educational institutions, they learn from a young age to relax, create and ease off dealing with music, dance, extreme sports, theatre, cinema and many more. Ilias, who has a low performance for a Law School in Greece, indicatively states:

"I will definitely study Law. My father is the well-known lawyer $\{$ A...\}. We have an office in Athens and collaborators all over Greece. Only someone crazy would change professional orientation. OK, I am a painter all alone $\{\ldots\}$ "

Children whose parents are doctors in public hospitals are especially preoccupied. Since the profession undergoes a crisis, too, and the professional continuation is not sure, the girls mainly choose other professional fields avoiding long-term studies with an unsure outcome. Even in this case the professions that they apply for are professions of a high social status and are not connected to the civil servant relationship. Children whose parents are businessmen are 
of special interest. They choose specialized economics studies. Among the students having high performance the first choice out of the universities abroad are those ones in the United States, especially in the fields of Technology and Economics. In those cases when there is not a professional continuation of the father's or the mother's job, the children being already travelers and having a good internet communication through their knowledge of foreign languages redefine the concept of "place" as an environment that creates financial opportunities for the individuals. Alicia's observation is indicative:

"I want to live in Paris. I am going to involve myself with design. I will meet my parent whenever I want $\{\ldots\}$ Is there any chance to see more of them at the moment?"

There is also interest in those stating that they want to become politicians. They define the word "politician" as a profession. When they were requested to grade which professions have the greater social insecurity they themselves filled in and ranked the word "politician" as the profession with the slightest risk. The concept of politician as a profession was expressed individually by boys who emphasized the financial security as well as the political, social and financial possibilities that are generally given to politicians as individuals and to their families. It is characteristic that they did not mention at all elements of ethics which emphasize the change of politics, the image of the politician as a reformer for the better future of society or humanity. An observation made by children coming from parents being military officers is very interesting. They do not apply for any military academy. They do not wish the dependence and submission relationship that exists within the hierarchical pyramid. Apostolos indicatively observes:

"When I was young my father, at an unsuspected time, said in the house "at your command!" \{...\} Now that he is a career officer I always listen to other people saying "at your command! \{...\}I do not want to order or to be ordered. What do I want? I want his money to go to England. I am going to study computers"

The issue of their professional occupation is not what they seek for within the family not even within peers. From the moment a child chooses a field, further elements about the university, the departments potentials and financial issues, tuition and other costs are investigated. Maria's observation is indicative:

"Each one of us knows where to go or better to say to which country. Basically, I do not care what they are going to do. Sometimes I remember someone because s/he said something strange $\{. .$.$\} and I asked him/her what it is. Do not$ ask me more questions. It is spring and I am in love"

It is characteristic that families tend to be irrelevant regarding their girls' choices reproducing through different terms the same stereotype that a man's professional role is more important than the one a woman has. On the one hand, the boys choose more often fields such as law, medicine, economics etc. On the other hand, the girls are usually diversified by choosing humanitarian schools or those of specialized artistic interest.

\section{Conclusions}

On the basis of the findings it is suggested that most male and female students of this age deal especially with the issue of their professional occupation connected to the choice of their studies. The Greek society concentrates on the issue of the students' entrance into Tertiary Education expecting even during the crisis that the higher studies will create good perspectives for their professional occupation. During a crisis, a focus on disciplines with specific professional perspectives is observed. Both upper and lower social strata giving or not to the teenagers initiative tend to guide them, directly or indirectly, to studies with a specific subject. This issue must be evaluated as an important one because in the following years university schools without professional rights or unspecific subject of studies will be disdained. It is sure that the upper social strata will be hit less by the crisis and their children will have a better professional evolution because they have the possibility to utilize and take advantage of wide communication information systems, so that their children are familiarized with structures and systems. Therefore, although it is apparent in the research that they themselves decide a semantics analysis of their viewpoint, it would prove that the elements of the dominant culture that are diffused in their family and educational environment formulate their perceptions, attitudes and choices.

The gap between the upper and lower strata will be investigated, the lower social strata will be limited in maintaining their vested rights, mainly the financial ones, as a result of the financial prosperity of the previous period, an issue connected to the attempt of reserving labor positions and less to undertaking the risk that would be obviously linked to the social mobility and the relevant involvement in political decision-making centers or in a professional occupation in fields of increased prestige.

A fall back is estimated to appear especially in the lower strata with a better education provided for the boys. Therefore, the girls will be in a worse position since their typical qualifications will be decreased and should the already formulated inequality due to social classes be co-estimated, it is obvious that, in practice, many women's 
rights will be cancelled and the whole attempt made within the framework of positive discrimination to embody women in the decision-making centers and strategy formation in political and financial fields, is cancelled.

Another observation is that the lower strata choose the security of the public sector and this is why they guide boys mainly to schools directly related to the public sector such as military academies. Statistics show the ongoing tendency of the grading necessary for the military and police academies. There are interesting observations of children coming from the lower strata which refer to professional choices. They decide together with their father, thus, it is noticed that the father's position in the family is in accordance with the traditional model in which serious decision-making basically on financial and professional issues is done by him. One would comment the end of adolescence for male and female students when they come to deal with their professional future. They attend courses and dedicate many hours in studying or tutorial institutions losing unique moments as teenagers. At this point, a differentiation should be made underlining, as it has already been mentioned, that the children of the upper social classes have less anxiety, a wider range of choices, a social and financial background offering stability and the potential to enjoy some personal moments by utilizing their free time in experimentation and involvement with sports, dance and music. They are prepared, in a formal and non formal manner, to become members of the upper social class. On the contrary, the lower strata, during the financial crisis, decrease any expenditures related to well-being, satisfaction and pleasure.

The issue of choosing a university seems to be transferred far from the issue of preference since, for various reasons, both in the lower and upper strata individuals are constrained to make a choice. Even in the upper social strata that seem to have a wider range of choices the professional success is what the candidates are looking for and it is evaluated. The issue of our consideration is what they would do if the financial crisis did not exist. The data for the lower strata is that there would be a relaxation as a result of security that this financial situation would continue together with the client-like system that would give the individuals the possibility to occupy themselves in professional terms. Unemployment as well as the corresponding fear of marginalization and exclusion does not exist.

To top it all, it is observed that within the superior social strata in the area of the Northern suburbs the choices of studying are irrelevant of the high or low students' school performance. Basic studies or postgraduate studies abroad are mainly chosen and it seems that the Greek educational system is disdained. In the lower strata where the low social and educational capital is dominant the children are not given the initiative to choose; the issue of preferences and choices is not taken into consideration although Tertiary Education remains the main target even for this group of people. They tend to address the issue of labor as one of great importance so that male and female students of these social strata are ready to enter earlier the labor market. Concentration was basically placed on issues related to the individual's personality, his/her possibility or not to illustrate his/her preferences, the potential or not to live his/her adolescence, the possibility or not to participate in a superior civilization, as this is formulated through the educational culture. A serious issue of consideration is that of seeking labor stability related to social acceptance. It mainly leads the children of lower strata to choose schools directly linked to the public sector, thus, a new "brain drain" will be created, since the contribution of potential talents or new researchers that would promote innovations in different social, financial and other fields is excluded.

By examining the young people's answers, one could notice that the "right to the dream" is limited, the youngsters feel suffocated within an environment of general disapproval and insecurity something which, in a different way, is perceived by the higher strata where the financial easiness and the family's social capital creates opportunities and reduces disappointment.

A political model that refers to the financial development and innovation is dysfunctional without the youngsters' action, without their active participation in a course of financial restoration, experimentation, pioneer proposals and innovative strategies. Therefore, a welfare state should be reinforced, that will re-evaluate the provisions towards the lower strata, such as scholarships and special financing so that these individuals are encouraged to draw a new professional and educational course corresponding to their special possibilities, talents and interests.

\section{References}

Apple, M.W. (1982). Education and power. London: Routledge \& Kegan Paul.

Ball, J. S. (2008). The education debate: Policy and Politics in the Twenty-First Century (Policy and Politics in the Twenty-first Century Series. Great Britain: The Policy Press.

Barnes, B. (1977). Interests and the growth of knowledge, London: Routledge and Kegan Paul.

Barrow, C.W. (1990). Universities and the capitalist state: Corporate liberalism and the reconstreuction of American higher education, 1894-1928. Madison: University of Wisconsin Press. 
Bauman, Z. (2000). Liquid modernity, Cambridge: Polity Press.

Bauman, Z. (2002). Society under siege, Cambridge: Polity Press.

Beck, J. (1999). "Makeover or Takeover? The Strange Death of Educational Autonomy in Neo-liberal England". British Journal of Sociology of Education, 20, 223-38. http://dx.doi.org/10.1080/01425699995425

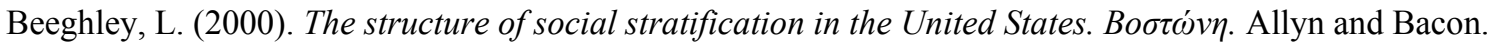

Bernstein, A. (2003). "Waking up from the American Dream: Dead-end jobs and the high cost of college could be choking off upward mobility”. Business Week online $1 \Delta \varepsilon \kappa$.

Best,S. \& Kellner, D. (2001). The postmodern adventure: Science, technology and cultural studies at the third millennium, New York: Guilford Press.

Bijker, W., Pinch, T. \& Hudges, T. (eds) (1987). The social construction of technological systems: New directions in the sociology and history of technology, Cambridge, Mass: MIT Press.

Bluck, S. \& Habermas, T. (2000). The life story schema. Motivation and Emotion, 24, 121-147. http://dx.doi.org/10.1023/A:1005615331901

Bochner, A.P. (2001). Narrative's virtues. Qualitative Inquiry, 7, 131-157. http://dx.doi.org/10.1177/107780040100700201

Bourdieu, P. (1986). "The Forms of Capital", in Handbook of Theory and Research for the Sociology of Education, edited by Richardson, J.G. New York: Grennword press, 241-159.

Bourdieu, P. (1996). Distinction. A Social Critique of the Judgment of Taste. London: Routledge.

Bowles,S. \& Gintis , H. (1976). Schooling and capitalist America. New York: Basic Books.

Castells, M. (1996). The rise of the network society. Malden, MA: Blackwell.

Castells, M. (1997). The power of identity. Malden, MA: Blackwell.

Collins, R. (1979). Credential society. New York: Academic Press.

Crotty, M. (1998). The foundations of social research: Meaning and perspective in the research process. London: Sage.

Denzin, N.K. (2009). The research act: A theoretical introduction to sociological methods. New Brunswick, NJ: Aldine Transaction.

Elliott, A. \& Turner, B.S. (2001). Profiles in contemporary social theory. London: Sage.

Erben, M. (1993). "The problem of Other Lives: Perspectives on Written Biography". Sociology.27(1) 15-25. http://dx.doi.org/10.1177/003803859302700103

Ericsson, K.A., \& Simon, H.A. (1980). Verbal reports as data. Psychological Review, 87(3), 215-251. http://dx.doi.org/10.1037/0033-295X.87.3.215

Etzioni, A. (2004). The post affluent society. Review of Social Economy 62, 407-420. http://dx.doi.org/10.1080/0034676042000253990

Fraser, M., Kember, S. \& Lury,C. (2005). "Inventive life. Approaches to the new vitalism" Theory, culture and society, 22(1): 1-14. http://dx.doi.org/10.1177/0263276405048431

Foucault, M. (1980). Power/ Knowledge. Selected Interviews and Other Writings 1972-77. Hemel Hempstead: Harvester Wheatsheaf.

Geertz, C. (1983). Local knowledge: Further essays in interpretative anthropology, New York: BasicBooks.

Gibbons, M., Limoges, C., Nowothy, H., Schwartzman, S., Scott, P. \& Trow, M. (1994). The new production of knowledge: The dynamics of science and research in contemporary societes. London: Sage Publications.

Giddens, A. (1984). The Constitution of Society. Cambridge: Polity Press.

Gould, St. J. (1989). Wonderful life: The burgess shale and the nature of history. New York: W.W.Norton \& Co.

Harding, S. (1991). Whose Science, Whose Knowledge? Ithaca. N.Y: Cornell University Press.

Hardt, J. \& Rutter, M. (2004). Validity of adult retrospective reports of adverse childhood experiences: Review of the evidence. Journal of Child Psychology and Psychiatry, 45-260-273. 
Hardt, M. \& Negri, A. (2000). Empire. Cambridge, MA: Harvard University Press.

Huq, R. (2006). Beyond subculture. London: Routledge.

Laurent, G. \& Kapferer, J.N. (1985). Measuring consumer involvement profiles. Journal of Marketing Research, 22, 41-53. http://dx.doi.org/10.2307/3151549

Lash, S. \& Urry, J. (1987). The end of organized capitalism. Cambridge, UK: Polity Press.

Law, J. \& Mol, A. (eds) (2002). Complexities. Social studies of knowledge practices. Durham-London: Duke University Press.

Lewis, M. (1980). Time frames: The meaning of family pictures. New York: Random House.

Maanheim, K. (1936). Ideology and utopia. New York: Harvest Books.

Maasen, S. \& Weingart, P. (2000). Metaphors and the dynamics of knowledge. London: Routledge.

Miller, C.C., Cardinal. L.B \& Glick, W.H. (1997). Retrospective reports in organizational research: A reexamination of recent evidence. Academy of Management Journal, 40, 189-204. http://dx.doi.org/10.2307/257026

Mitchell, E.D., Crowson, R.L., \& Shipps, D. (2011). Shaping Education Policy. Power and Process. New York\& London: Routledge.

Nelson, K. (1993). The psychological and social origins of autobiographical memory. Psychological Science, 4, 7-14. http://dx.doi.org/10.1111/j.1467-9280.1993.tb00548.x

Nisbett,R. , \& Wilson,T.D. (1977). Telling more than we can know: Verbal reports on mental processes. Psychological Review, 84, 231-259. http://dx.doi.org/10.1037/0033-295X.84.3.231

Nowothny, H., Scott, P. \& Gibbons, M. (2001). Re-thinking science: Knowledge and the public in an age of uncertainty. Cambridge: Polity Press.

Plummer, K. (1995). Telling Sexual Stories. London: Routledge. http://dx.doi.org/10.4324/9780203425268

Plummer, K. (2001). Documents of life 2. An Invitation to a Critical Humanism. London: Sage.

Polkinghorne, D. (1988). Narrative knowing and the human sciences. Albany, NY: State University of New York Press.

Prus, R. (1996). Symbolic interaction and ethnographic research: Intersubjectivity and the study of human lived experience. New York: State University of New York Press.

Ritzer, G., Goodman, D. (2004). Modern sociological theory. New York: McGraw-Hill.

Rizvi, F. \& Lingard, B. (2009). Globalizing Education Policy . New York: Routledge.

Robbins, D. (2005). The origins, early development and status of Bourdieu's concept of cultural capital. The British Journal of Sociology.56 (1), 13-30. http://dx.doi.org/10.1111/j.1468-4446.2005.00044.x

Roberts, B.W., Walton, K.E., \& Viechtbauer, W. (2006). Patterns of mean-level change in personality traits across the life course: A meta-analysis of longitudinal studies. Psychological Bulletin, 132 (1), 1-25. http://dx.doi.org/10.1037/0033-2909.132.1.1

Ross, M. (1989). Relation of implicit theories to the construction of personal histories. Psychological Review, 96, 341- 357. http://dx.doi.org/10.1037/0033-295X.96.2.341

Stein, J. S. (2004). The Culture of Education Policy. New York: Teachers College, Columbia University.

Strauss, A. \& Corbin, J. (1990). Basics of Qualitative Research: Grounded Theory Procedures and Techniques. London: Sage.

Sykes,G., Schneider B., \& Plank, D.N. (2009). Handbook of Education Policy Research. New York: Routledge.

Taylor, M. (2003). The moment of complexity: Emerging network society. Chicago: University of Chicago Press.

Werthington, E. (2000). Life stories: Integrating quantitative and qualitative approaches. Motivation and Emotion, 24 (2), 63-66. http://dx.doi.org/10.1023/A:1005680730084

Wiersma, W. \& Jurs S.G. (2008). Research Methods in Education: An Introduction, $9^{\text {th }}$ Edition. London: Pearson. 